\title{
High dose dexamethasone treatment for Acute Respiratory Distress Syndrome secondary to COVID-19: a structured summary of a study protocol for a randomised controlled trial
}

Luis Patricio Maskin ${ }^{1,2^{*}}$ (D), Gabriel Leonardo Olarte ${ }^{3}$, Fernando Palizas $\mathrm{Jr}^{4}$, Agostina E. Velo ${ }^{1}$, María Fernanda Lurbet ${ }^{1}$, Ignacio Bonelli ${ }^{1}$, Natalio D. Baredes ${ }^{3}$ and Pablo Oscar Rodríguez ${ }^{1,2^{*}}$

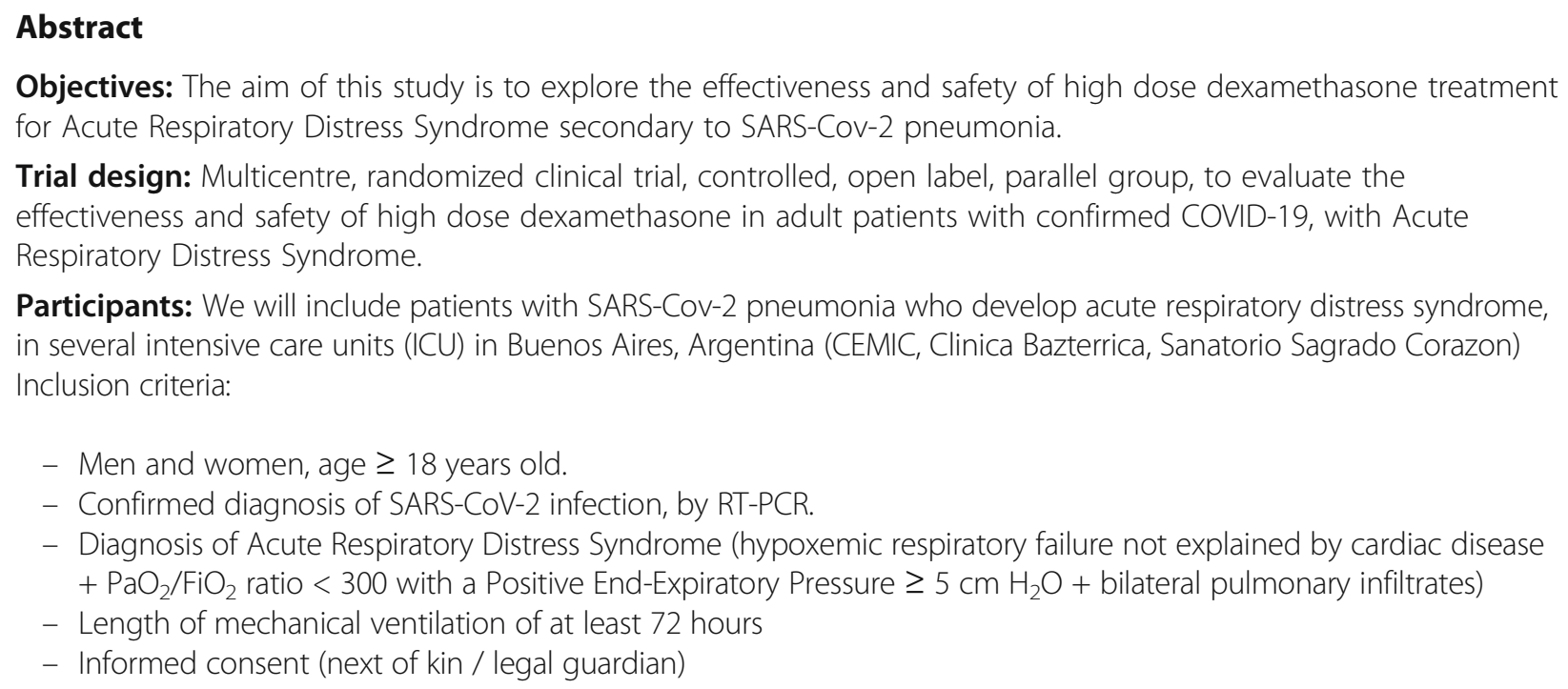

Objectives: The aim of this study is to explore the effectiveness and safety of high dose dexamethasone treatment for Acute Respiratory Distress Syndrome secondary to SARS-Cov-2 pneumonia.

Trial design: Multicentre, randomized clinical trial, controlled, open label, parallel group, to evaluate the effectiveness and safety of high dose dexamethasone in adult patients with confirmed COVID-19, with Acute Respiratory Distress Syndrome.

Participants: We will include patients with SARS-Cov-2 pneumonia who develop acute respiratory distress syndrome, in several intensive care units (ICU) in Buenos Aires, Argentina (CEMIC, Clinica Bazterrica, Sanatorio Sagrado Corazon) Inclusion criteria:

- Men and women, age $\geq 18$ years old.

- Confirmed diagnosis of SARS-CoV-2 infection, by RT-PCR.

- Diagnosis of Acute Respiratory Distress Syndrome (hypoxemic respiratory failure not explained by cardiac disease $+\mathrm{PaO}_{2} / \mathrm{FiO}_{2}$ ratio $<300$ with a Positive End-Expiratory Pressure $\geq 5 \mathrm{~cm} \mathrm{H}_{2} \mathrm{O}+$ bilateral pulmonary infiltrates)

- Length of mechanical ventilation of at least 72 hours

- Informed consent (next of kin / legal guardian)

Exclusion criteria:

- Pregnant or breast-feeding women.

- Terminal disease (advanced cancer; under palliative care; cardiovascular, respiratory, or renal disease with a life (Continued on next page)

\footnotetext{
* Correspondence: pmaskin@cemic.edu.ar; prodriguez@cemic.edu.ar

${ }^{1}$ Intensive Care Unit, CEMIC, Buenos Aires, Argentina

Full list of author information is available at the end of the article
}

(c) The Author(s). 2020 Open Access This article is licensed under a Creative Commons Attribution 4.0 International License, which permits use, sharing, adaptation, distribution and reproduction in any medium or format, as long as you give appropriate credit to the original author(s) and the source, provide a link to the Creative Commons licence, and indicate if changes were made. The images or other third party material in this article are included in the article's Creative Commons licence, unless indicated otherwise in a credit line to the material. If material is not included in the article's Creative Commons licence and your intended use is not permitted by statutory regulation or exceeds the permitted use, you will need to obtain permission directly from the copyright holder. To view a copy of this licence, visit http://creativecommons.org/licenses/by/4.0/ The Creative Commons Public Domain Dedication waiver (http://creativecommons.org/publicdomain/zero/1.0/) applies to the data made available in this article, unless otherwise stated in a credit line to the data. 
(Continued from previous page)

expectancy less $\leq 1$ year).

- Therapeutic limitation (advance directives or do not resuscitate order)

- Severe immunosuppression (HIV infection, long-term use of immunosuppressive agents, active cancer).

- Patients under chronic treatment with glucocorticoids for other diseases ( $\geq 8 \mathrm{mg}$ prednisone, or equivalent)

- Participation in another randomized clinical trial.

Intervention and comparator: Eligible patients will be randomized to receive standard ICU patient care (group 1) or standard ICU patient care plus high dose dexamethasone (group 2).

- Group 1: dexamethasone up to 6 mg/24 hours for up to 10 days + ventilatory, hemodynamic, nutritional, and antimicrobial support according to international guidelines.

- Group 2: dexamethasone 16 mg/24 hours for 5 days followed by dexamethasone 8 mg/24 hours for 5 days + ventilatory, hemodynamic, nutritional, and antimicrobial support according to international guidelines.

Main outcome: The main result is ventilator-free days at 28 days (Days without ventilator support in the first 28 days following randomization). Secondary outcomes are 28-days and 90-days mortality, frequency of nosocomial infections in the first 28 days after randomization, Sequential Organ Failure Assessment (SOFA) score variation and prone position in the first 10-days, viral shedding 28-days after randomization, and delirium and muscle weakness at ICU discharge.

Randomisation: Treatment will be assigned according to site stratified randomization by permuted random blocks sequence 1:1 generated with a table in R language concealed in a randomization tool in REDCap (Research Electronic Data (APture) platform.

Blinding (masking): This is an open trial, so no masking of treatment assignment will be used.

Numbers to be randomised (sample size): Assuming a 3 days difference in ventilator-free days between treatment groups, with a mean of 9 days, and a standard deviation of 9 days; the necessary sample size would be 284 subjects (142 per group), with a power of $80 \%$ and a two-tailed alpha error of 0.05 .

Trial Status: The protocol with code 1264, version 3.0 on date: May 13, 2020 is approved by the local Ethics Committee. The trial is in the recruitment phase. Recruitment began May 22, 2020 and is anticipated to be complete by the end of December 2021.

Trial registration: The trial was registered under the title "Dexamethasone for COVID-19 Related ARDS: a Multicenter, Randomized Clinical Trial" with ClinicalTrials number NCT04395105, https://clinicaltrials.gov/ct2/show/NCT04395105, registered on 20 May 2020.

Full protocol: The full protocol is attached as an additional file, accessible from the Trials website (Additional file 1). In the interest in expediting dissemination of this material, the familiar formatting has been eliminated; this Letter serves as a summary of the key elements of the full protocol.

Keywords: COVID-19, Dexamethasone, Acute Respiratory Distress Syndrome, Randomised controlled trial, protocol, Steroids

\section{Supplementary information}

Supplementary information accompanies this paper at https://doi.org/10. 1186/s13063-020-04646-y.

Additional file 1. Study protocol.

\section{Acknowledgements}

Not applicable.

\section{Authors' contributions}

The protocol was conceived and drafted by LPM \& POR, and all authors were involved in review, amendments, and approval of the final protocol. POR had primary responsibility for statistical methodology. The authors read and approved the final manuscript.

\section{Funding}

There is no funder for this study. There has been no involvement of funding sources in the study design; in the collection, analysis, and interpretation of data; in the writing of this manuscript; or in the decision to submit the article for publication.

\section{Availability of data and materials}

The data will be available from the author on reasonable request. Please contact the corresponding author Dr Pablo O. Rodriguez (prodriguez@cemic. edu.ar).

\section{Ethics approval and consent to participate}

The protocol was evaluated by the Local Research Ethics Committee of CEMI C (Buenos Aires, Argentina), on May 13, 2020 with the reference code 1264. It was approved on May 13, 2020.

Patient's next of kin will be asked for informed consent. This will be reflected in the medical record before included in the clinical trial. A copy of the informed consent will be attached in the medical record.

Consent for publication

Not applicable 


\section{Competing interests}

The authors declare that they have no competing interests.

\section{Author details}

'Intensive Care Unit, CEMIC, Buenos Aires, Argentina. ${ }^{2}$ Pulmonary Section, Internal Medicine Department, CEMIC, Buenos Aires, Argentina. ${ }^{3}$ Intensive Care Unit, Sanatorio Sagrado Corazon, Buenos Aires, Argentina. ${ }^{4}$ Intensive Care Unit, Clinica Bazterrica, Buenos Aires, Argentina.

Received: 28 July 2020 Accepted: 30 July 2020

Published online: 26 August 2020

\section{Publisher's Note}

Springer Nature remains neutral with regard to jurisdictional claims in published maps and institutional affiliations.

Ready to submit your research? Choose BMC and benefit from:

- fast, convenient online submission

- thorough peer review by experienced researchers in your field

- rapid publication on acceptance

- support for research data, including large and complex data types

- gold Open Access which fosters wider collaboration and increased citations

- maximum visibility for your research: over $100 \mathrm{M}$ website views per year

At BMC, research is always in progress. 